\title{
QUEST EXCURSION, AS INTERACTIVE FORM OF PROVIDING EXCURSION SERVICES IN KAZAKHSTAN
}

\author{
Anastassiya GUBARENKO* \\ Kazakh Academy of Sports and Tourism, Department of Tourism and Service, \\ Ave. Abay 85, Almaty 050022, Almaty, Republic of Kazakhstan, e-mail: gerseda@mail.ru
}

\section{Dinara KADYRBEKOVA}

Kazakh Academy of Sports and Tourism, Department of Tourism and Service, Ave. Abay 85, Almaty 050022, Almaty, Republic of Kazakhstan, e-mail: 6537275@mail.ru

Tatyana IMANGULOVA

Kazakh Academy of Sports and Tourism, Department of Tourism and Service, Ave. Abay 85, Almaty 050022, Almaty, Republic of Kazakhstan, e-mail: tanya_geo@mail.ru

\section{Oleg LUTEROVICH}

Kazakh Academy of Sports and Tourism, Department of Tourism and Service, Ave. Abay 85, Almaty 050022, Almaty, Republic of Kazakhstan, e-mail: oleg_tur_53@mail.ru

\section{Nurkeldi YESPENBETOV}

Kazakh Academy of Sports and Tourism, Department of Tourism and Service, Ave. Abay 85, Almaty 050022, Almaty, Republic of Kazakhstan, e-mail: espenbetov87@mail.ru

\begin{abstract}
Citation: Gubarenko, A., Kadyrbekova, D., Imangulova, T., Luterovich, O., \& Yespenbetov, N. (2020). QUEST EXCURSION, AS INTERACTIVE FORM OF PROVIDING EXCURSION SERVICES IN KAZAKHSTAN. GeoJournal of Tourism and Geosites, $32(4)$, 1402-1409. https://doi.org/10.30892/gtg.32431-587
\end{abstract}

\begin{abstract}
In this article, the authors give a clear definition of interactive forms of excursions, the process of organizing and implementing them in educational and professional activities in the field of excursion services. Special attention is paid to the experimental-empirical methods for creating author's quest-excursions of the different focuses, as unique means of tourist and local history, excursion and research work of specialists in the field of hospitality. The authors have developed and implemented six uniquely designed quest excursions, on the example of Almaty city.
\end{abstract}

Key words: excursion service, tourism, quest excursion, attraction

\section{INTRODUCTION}

Nowadays, more and more attention is paid to the domestic and inbound tourism development as the most promising and economically important areas in the world tourism market. In the articles, publications and research works international organizations such as UNWTO, UNESCO, WFTGA, WTO, etc. speak primarily about the development of regional tourism, more of authentic direction. The leader of the nation, Elbasy N.A. Nazarbayev and the current president of the Republic of Kazakhstan, KassymJomartTokayev, repeatedly emphasized the need for significant development of tourism in the country.

Thus, the tourism industry experts faced the following difficult task: the development of tourist destinations, the development of innovative means of attracting tourists, improving the quality of excursion services and hospitality. At the present stage of its development, the excursion services are not just a way to organize leisure and educational activities in an urban or natural environment, today, it is a way to actively involve tourists in the excursion route by creating conditions in which the tourist turns from a listener into a participant who researches, analyzes and interprets the material in order to solve the tasks assigned to him. All this is pos sible only when developing innovative forms and methods of excursion services, which in turn is possible only with serious research and organizational work of specialists in the tourism industry. This research is based on the works of domestic and foreign scientists, as well as the experience of the world's leading organizations in the field of tourism, organization of excursion services and animation events. So, a special place in the study is occupied by international experience, quest-excursions developed in the European space are distinguished by their interactivity and historicity, while combining all the necessary features of an excursion, the term.

An excursion is one of the most effective methods of active-motor learning, considering its main property to be mobility. In his opinion during movement in space various motor sensations give a very special character to the intellectual and emotional experiences of an excursionist (Raikov, 1922).The scientist and tour guide, who headed General Excursion Department of the Central Council for Tourism and Excursions from 1969 to 1988, defines excursion as follows: "a methodically arranged process of viewing of places of interest, historical and cultural monuments, which is based on the analysis of objects before the eyes of tourists, as well as a smart report of events related to them" (Yemelyanov, 2001). Excursion is a purposeful, visual process of learning the world around us, associated with pre-selected objects, theme and route, under the guidance of a qualified specialist (Tătar et al., 2018).

Kazakh researchers believe that "excursion is a visit by an individual to tourist resources for educational purposes in the country (place) of temporary stay for no more than twenty-four hours" (Yagofarov and Lyuterovich, 2016). So now, we have a clear idea of the term "excursion", which reflects all the elements of this concept in the traditional sense, but interactive excursions (quests, theatrical elements, animation, etc.) have a number of distinctive features and specific characteristics, which undoubtedly require additions and comparisons. The traditional excursion is a form of cognitive and recreational activity, which is primarily aimed at show-and-tell, with the use of techniques of

\footnotetext{
${ }^{*}$ Corresponding author
} 
enhancing attention, thus, the informative part dominates in front of entertainment. Meanwhile, the quest excursion is not traditional, educational, museum, city or country excursion, but it is arranged in the search and game form and targeted equally on leisure, entertainment, animation, and quite eventful in the field of information content and cognition. Highlighting the tourist guides' role in developing and sustaining the local economy is a sine-qua-non condition that is increasingly necessary both locally and nationally.

\section{MATERIALS AND METHODS}

The article is based on the literature review research of domestic and foreign scientists, research and systematization of materials, development of innovative methods of experimental and empirical level. The experience of the CIS countries, scientists, whose work is aimed at the development of excursion services, various methods of active cognition, was studied. So, in various works, the term "quest excursion" is interpreted in different ways, there are several variations of it, so the most common: quest excursion, tasks excursion, quest tour, excursion-quest and so on. Each term has its own specifics, in this regard, we have defined the term "quest excursion" as the most appropriate, since it is the one which reveals the specifics of the direction of research, namely the study of excursion objects and attractions, by solving puzzles of various orientations by means of an excursion route to achieve final result, finish, treasure, etc. A quest excursion is the study of objects with the help of game tasks and a storyline through the development of new skills of information search and communication, and their application in a given situation (Alekseyeva, 2015) «Quest tour as an innovative form of excursion activity»;

The definition of this term from the perspective of children's tourism is the following: "A quest excursion is a game during which participants perform various tasks for logical thinking, acquiring the skills of interacting with a team, searching for information and the ability to apply it to achieve the ultimate goal of the mission" (Alexandrova, 2015).

In addition, quest excursion is a service for organizing visits to specially selected objects of excursion display by individual tourists (excursionists) or tourist groups, which consists of familiarity and exploration of these objects through observation, communication with other subjects and solving logical problems under the guidance of a qualified specialist - a guide, lasting less than 24 hours without an overnight stay «Quest tourism as an innovative form of tour» (Nekhayeva and Morozkina, 2017), in the works of these authors, this term is also used by the scientists (Bulygina et al., 2016). Their work has become the basis for organizing our research and made it possible to deepen the previously existing concepts and definitions (Kedrova, 2017); Quest-excursion as a form of modern excursion activities (Kuteeva and Pospelov, 2015) and interactive excursion activities (Pospelova, 2017).

The main method of research was experimental and empirical (Zhuravlev et al., 1998) that is a mixed method that combines observation, questionnaire survey, study of creative and experimental works of students, undergraduates, local historians and guides. The mixed methods research design was employed (Morgan, 2013), integrating quantitative and qualitative methods in data collection and analysis (Karatabanov et al., 2020). Applied the experimental and empirical methods, creative development, survey, etc. Applying the mix of methods makes it possible to conduct more extensive research, which is a special research strategy, where a researcher or a group of researchers combines elements of qualitative and quantitative research approaches (for example, the use of qualitative and quantitative optics, data collection and analysis procedures, etc.) for a comprehensive and deep analysis and solution of a wide range of problems (Burke and Onwuegbuzie, 2004). During the sociological survey of respondents, in which more than 200 people, residents of the city of Almaty, of various age groups took part, allowed to form the directions for the development of excursions-quests. Exactly they determined the direction of the experimental part of the study. The survey results have become the key for the experiment on the development and implementation of the results in the tourism offer of Almaty companies (Republic of Kazakhstan). Also, they were presented at the Republican Competition of Tourism Industry Specialists of the Kazakhstan Tourism Association (Almaty, Republic of Kazakhstan, 2019).

\section{RESULTS AND DISCUSSION}

The result of the research was the definition of the specific features of the term "quest excursion", as well as the experience of foreign countries was studied, a methodology for creating excursions-quests was developed, author's excursions quests were created and implemented. The research results are presented below.

The most important distinctive features of the quest excursion are the following:

- excursionists should independently obtain the information about excursion objects, sights, objects of the tour route, i.e. the tourist becomes an active participant in the educational and entertainment process, where a special role is given not only to information, but also to the physically active part of the quest excursion;

- the presence of a clear storyline that allows tourists to follow the course of events, while maintaining the interest of the excursionist and histher desire to achieve the goal of the quest excursion;

- the main goal is to get acquainted with historical facts, characters, sightseeing objects, despite the fact that a fairly large part of the excursion is an active solution of the tasks set for tourists, but the result is still information about the objects of the excursion route.

The comparative analysis presented in figure 1 will allow us to fully assess the features of the two main directions in the organization of excursion services: a traditional excursion (themed, observational, natural historical, etc.) and a quest excursion of the different focuses (traditional, sports, fantasy, intellectual, etc.) Thus, Figure 1 shows the distinctive features of the traditional excursion and quest excursion in the main areas: preparation, implementation and analysis of results. The results of this comparison allowed us to conclude that the quest excursion is not only highly interactive, but also requires thorough preparation.

Subsequently, for the further course of the research, it was necessary to conduct a sociological survey to determine priority directions in the organization of quest excursions, choice of locations, theme and focus, and the results of which became the starting point of the research, when it became the guidelines in the research organization.

A sociological survey conducted in August 2019, the results of which are shown in Figure 2, allowed us to determine exactly which sector of the tourism market is interested in conducting quest excursions, which areas in the development of the storyline are most interesting, which objects of tourist interest in Almaty are most suitable for the main criteria for organizing quest excursions, namely:

- the territory, the area of which allows conducting interactive activities of excursionists;

-the availability of excursion objects, attractions, and notable places that are informative enough and allow to form a sound knowledge of the history, culture, and nature of the destinations where the quest excursion can be held;

- the focus of the quest excursion, its storyline, often dictated by the place where the quest is held;

- the development of tasks that involve tourists in active educational and search activities and the storyline;

- the clear structure for completing tasks, when one solution allows you to start performing a new task, thus forming a "quest excursion scheme", as well as "start" and " finish";

-the availability of necessary documentation for the quest excursion: the tour route, the scheme of tasks and solutions, individual text of the excursion, etc.

- the ability to control the process of conducting the quest excursion by means of GPS, WhatsApp, Google Map and others.

- the availability of a guide and support staff necessary for the quest excursion. 


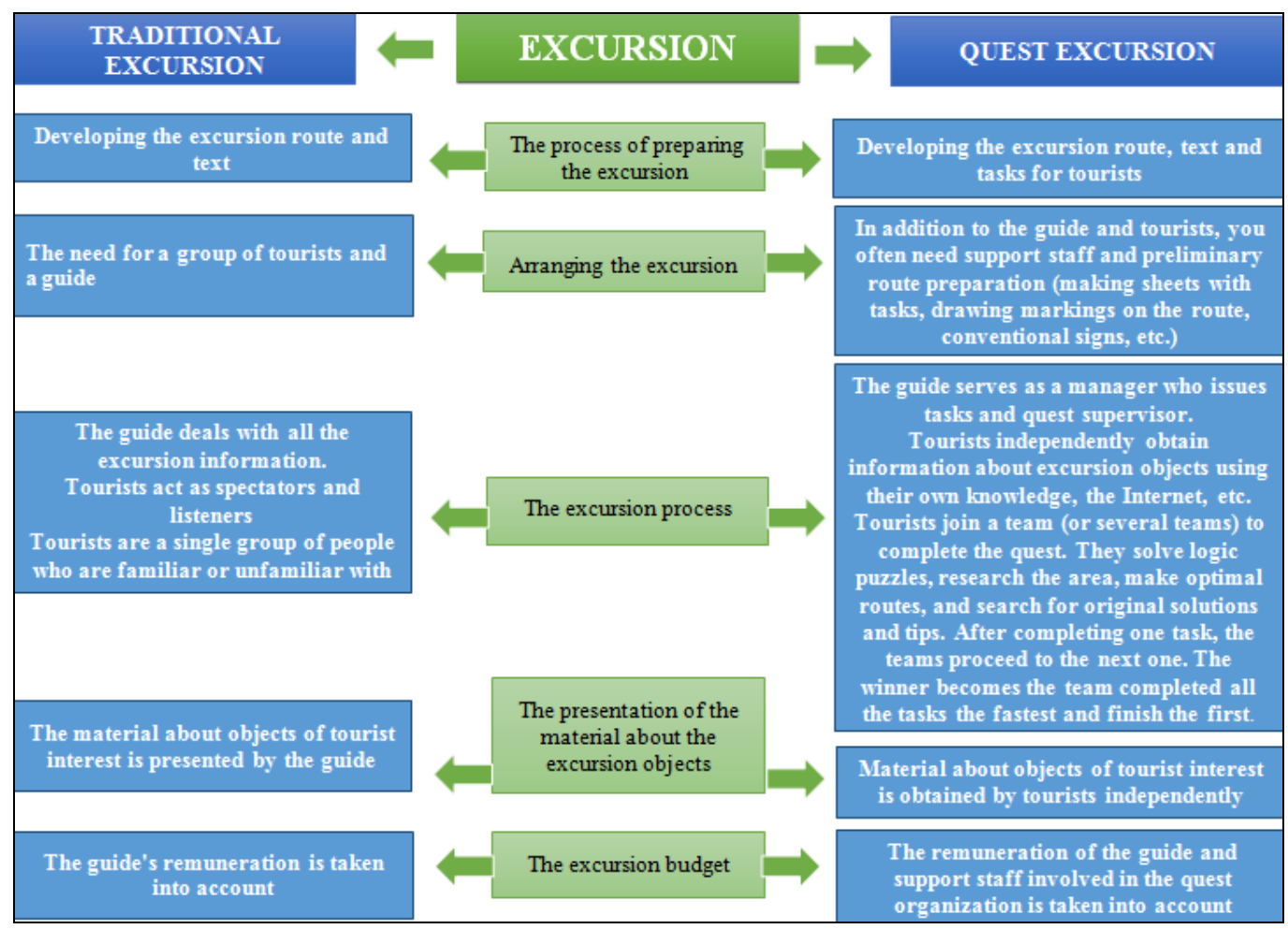

Figure 1. Comparative analysis of the traditional excursion and quest excursion (Source: compiled by the author)

We have analyzed the data obtained from the respondents during the survey, in which $65 \%$ were people aged from 18 to $24,16 \%$ - from 15 to $17,11 \%$ - from 25 to $34,7 \%$ - from 35 to 49 , over 50 - $1 \%$ (Figure 2 ).

The second question was: "What type of activity do you prefer the most?": 50\% of respondents prefer the outdoor quest excursion, $30 \%$ would choose the indoor quest excursion, and 20\% - the classic one (Figure 3).

The third question helped determine priorities in choosing tasks, namely, $46 \%$ of respondents prefer logic tasks, $31 \%$ - creative tasks, and $23 \%$ - sports tasks (Figure 4).

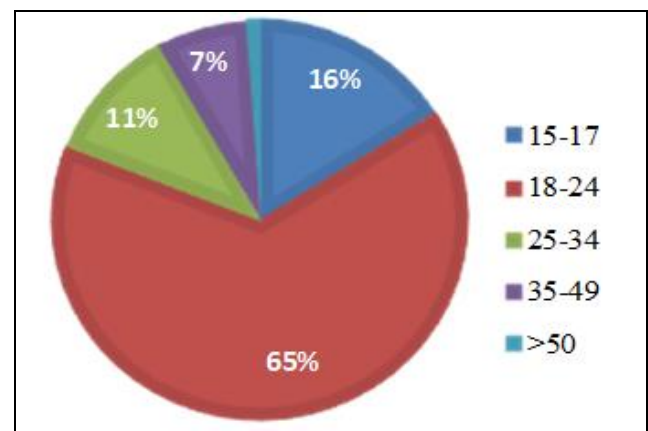

Figure 2.The analysis results of the sociological survey; Question 1(Age) (Source: compiled by the author)

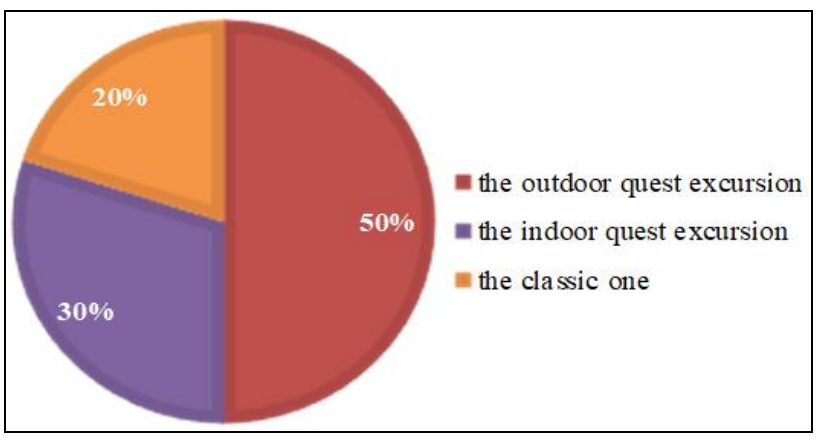

Figure 3.The analysis results of the sociological survey; Question 2 (What type of activity do you prefer the most?) (Source: compiled by the author)

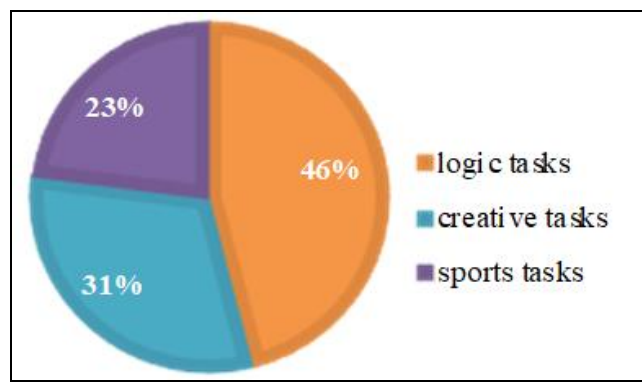

Figure 4. The analysis results of the sociological survey; Question 3 (Which quest tasks do you like the most?) (Source: compiled by the author)

Therefore, Figure 5 shows the results of a sociological survey in which more than 220 respondents took part. The survey shows that the most interesting quest excursions are tours of various focus, organized outdoors, in the parks and squares of the city. The next stage was the process of analyzing the world and regional experience in the preparation and implementation of interactive forms of excursions, namely quests. So, in international practice, two types of quest excursions are most in demand: one is conducted with the lead of a guide and other necessary staff, and the second is organized by means of new information technologies, and does not require direct participation of the organizers. In the countries of Europe and America, quest excursions have more than a century of history, so, at the preliminary stage of the research, which consists of collecting and analyzing information, as well as studying the world experience in the field of organizing quest 
excursions, we reviewed the experience of Latvia (Riga) and Sweden (Stockholm) in 2015. The organization of quest excursions, on the territory of these countries, has various themed focuses, but at the same time, historical quest excursions are the most popular.

So, the routes we have arranged were developed taking into account the informative saturation, i.e. the quest excursion was built on the basis of attractions in the historical center of the city. Tasks were logic puzzles, puzzles about history; to a greater extent they were of an authentic nature, and assumed full involvement in the culture of the country, as well as enrichment of knowledge about the current state and traditions of those cities. It is worth noting the essential elements of these quest excursions, namely the task sheet, maps and route diagrams, hidden tasks and objects of the quest, etc., which undoubtedly show the high quality of preparation for such events.

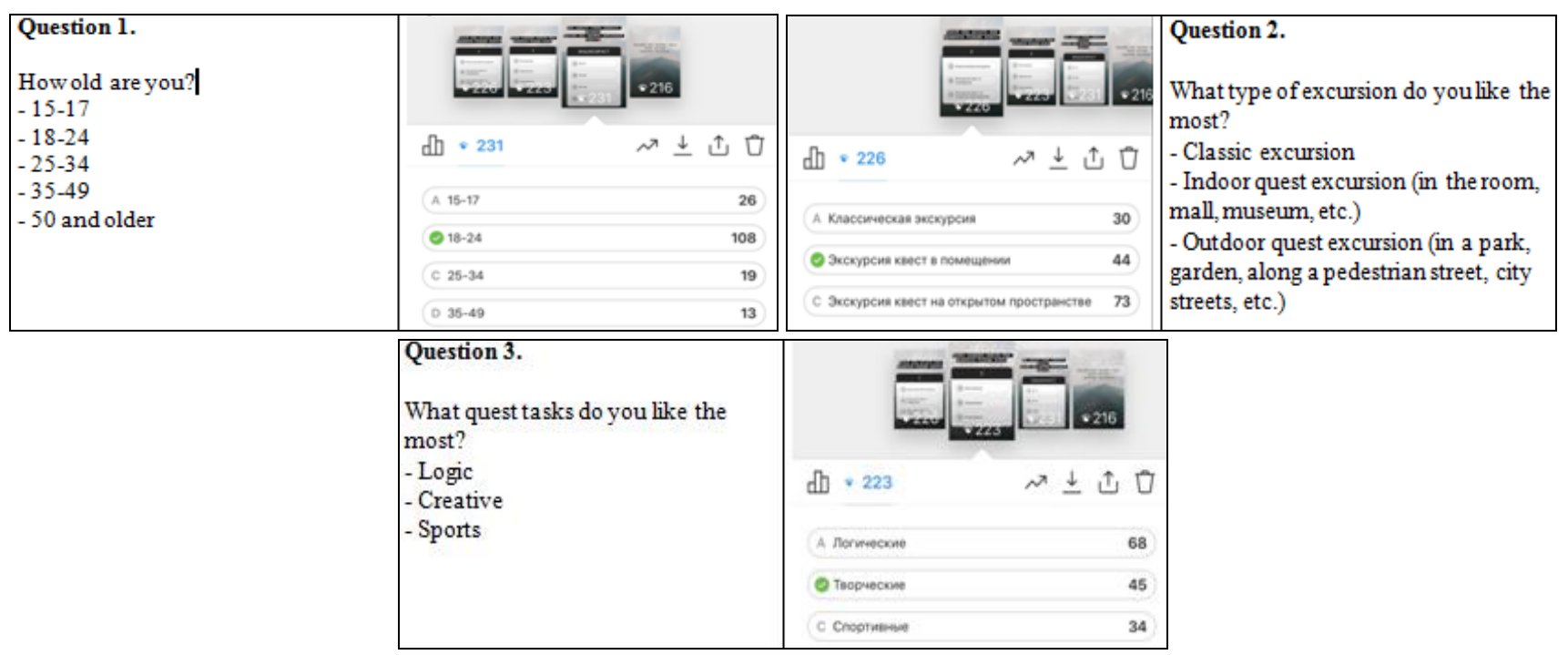

Figure 5. The results of the sociological survey (Source: compiled by the author)

In the post-Soviet space, quest excursions are just beginning to gain popularity among the general population and tourists. Work is underway to develop priority routes, identify locations, create quest excursions and implement them, popularize and promote them on the regional and international tourism market.

The practical part of the research is the process of developing a step-by-step plan and methodology for creating quest excursions, taking into account not only the results of a sociological survey, but also foreign and domestic experience in organizing and conducting quest excursions. The main locations were identified and their spatial information material was evaluated (Zakiryanov et al., 2018):

- Central Park of Culture and Leisure. The area is more than 42 hectares. It was founded in 1856, in the city of Verniy as State Garden (Russian: Kazennyy Sad). This park has an interesting history, and the presence of local history objects, monuments, legends and a diverse landscape contribute to the creation of unique projects, including quest excursions ( $43^{\circ} 15^{\prime} 45^{\prime \prime} \mathrm{N} 76^{\circ} 58^{\prime} 07^{\prime \prime} \mathrm{E}$, Almaty, Kazakhstan).

- First President's Park. The area is 53 hectares. It was founded in 2001 on the initiative of the First President N.A. Nazarbayev. It is a dendrological park, i.e. a wide variety of woody, shrubby and herbaceous plantings. Among the objects are park alleys, squares, monuments, an observation deck, a Japanese garden, the Jety Kazyna complex (Seven Treasures of the Kazakhs), as well as elements of landscape design $\left(43.188^{\circ} \mathrm{N} 76.887^{\circ} \mathrm{E}\right.$, Almaty, Kazakhstan).

- Park of 28 Panfilov Guardsmen. The area of the park is about 18 hectares. The park was founded in the second half of the 19-th century and is an object of local history. It is in this park that one of the world's 100 wonders of wooden architecture is located - the Holy Ascension Cathedral, objects of memorial and landscape significance ( $43^{\circ} 15^{\prime} 32.7^{\prime \prime} \mathrm{N} 76^{\circ} 57^{\prime} 10.7^{\prime \prime} \mathrm{E}$, Almaty, Kazakhstan).

- Pedestrian part of Panfilov Street. The length of the street is $3800 \mathrm{~m}$.; it is located in the historical part of the city and was laid at the end of the 19-th century. The street has an interesting historical development and has had a huge impact on the development of the entire city infrastructure. On the street there are historical objects, buildings and elements of urban infrastructure (Abay Opera House, Nedelka fountain, Zhambyl Zhabayev monument, Astana square, etc.), Almaty, Kazakhstan.

- MEGA Mall Alma-Ata, one of the largest objects in this area of activity in the country with a total area of $180,000 \mathrm{~m}^{2}$. On the territory of the mall there are entertainment centers, restaurants, shops, as well as art and decoration elements (fountains, statues, panel picture, etc.) (4312'9"N 7653'30"E., Almaty, Kazakhstan).

The above locations fully reflect the principles of creating and implementing the quest excursion, as not only with educational, informational, historical, but also entertainment and animation focus (Akbar et al., 2020). Thus, we can conclude that when choosing places, scenarios, tasks and stages of quest excursions, it is necessary to follow the next principles and stages:

1. The area of the location should correspond to the focus of the quest excursion, its features, specifics, the number of routes and the duration of their passage in time. So, a small area of the selected location can be justified by the presence of a single route, the number of objects involved in this route, and the quality (complexity) of the developed tasks. It should be understood that the larger the area of the location, the more options for creating a quest excursion, and the number of teams involved. The distance between the way points of the quest excursion route allows to implement a sports, animation, game and search part, while adjusting the time frame of the quest excursion, increasing or reducing the time spent to solve problems and move between the way points of the route;

2. Objects, attractions, way points form the route of the quest excursion. Their distinctive feature primarily depends on the information saturation of such objects, i.e., in contrast to the usual quest, the quest excursion is aimed at forming knowledge about the objects of the city located in a certain location, and collected in a single route, while it is necessary to divide the objects into Main and Accompanying. Thus, after defining the Main Points which are basic on the route, we could add Accompanying Points, which do not have much information richness, are able to diversify tasks and make a pause between complicated objects in terms of information. It is worth remembering that the amount of information that the average person can analyze for a limited amount of time without intellectual and emotional tiredness is not large and limited. In this regard, it is necessary to accurately classify quest excursions by focus (intellectual, cognitive, fantasy, sports, etc.) in order for the tourist to know exactly what to expect, while not forgetting about the excursion part of the quest excursion, i.e. the process of learning through search and play; 
3. The route of the quest excursion, developed in accordance with the selected location and combining the Main and Accompanying objects, in various variations, i.e. the presence of several route options or several different routes located in the same location. When developing routes for multiple teams, the following should be considered:

1) the time spent on the route options should be identical, i.e. when planning the "ideal minimum" time spent on the route with knowing all the solutions for the tasks, it should be the same for all route options, i.e. each route can be completed in equal times;

2) the complexity and number of tasks should be balanced and equal or equivalent for different routes, i.e. there are several options where this is possible: a) the same number and level of complexity of tasks, b) different number of tasks and the same total complexity;

3) start and finish. In most cases, there is one start and one finish point on different routes, this is quite convenient and in demand, but there is also a variant of a single start and different finish points, which may be due to the specifics of the routes themselves;

4) progress along the route is possible in a line directivity, i.e. the solution of one task allows to pass to the next object and solve the next task, etc.;

4. Tasks for the quest excursion should be developed in accordance with the focus (intellectual, cognitive, fantasy, sports, etc.), while taking into account high cognitive activity. These can be tasks about the objects and sights themselves, revealing their historical and cityforming role, architectural feature, local history aspect, etc., which is undoubtedly a priority in the development of tasks for the Main objects of the route, such tasks allow you to implement the excursion focus of these quests. Tasks should be developed in a logical sequence; they should be mutually dependent and interrelated with a single theme and focus. Also, special attention should be paid to the requirements: categories of complexity, information content, interactivity, usefulness and practical focus, tasks should be balanced, i.e. include various elements, also having a narrow focus of the quest excursion itself. Thus, we can say that the development of tasks for a quest excursion is a creative process that synthesizes information data and an entertainment and interactive component;

5. Substantive and support staff is one of the main features for the organization and conducting quest excursions. The availability of qualified specialists at all stages of preparation, development, implementation and conducting the quest excursion determines the quality of the final tour product. Like in traditional tours, so in the quest excursions the presence of a guide is necessary at different stages. For example, when selecting the location, the guide could assess the quality, quantity and richness of the objects (points) of route to form the path of the quest excursion, with developing the control and the individual text (if necessary), i.e., the tour guide creates a product, but, in the implementation process it is necessary to consider the scale of the work, namely, the presence of the coordinator, support staff and observers can qualitatively affect the result, and thus increase the positive effects of the quest excursion. Our experience gained during the development and implementation of quest excursions allows us to assess the importance of detailed selection of all personnel involved in this process. In addition, special attention should be paid to qualitative characteristics, skills in the field of information technology, minimal knowledge of history, local history, ethnography, etc. and detailed involvement in the process of preparing and implementing quest excursions;

6. Resources concept combines all the elements necessary for the implementation of the quest excursion, namely, printed maps and routes (in the full version for the organizers and special for participants), tasks (cards, sheets, crosswords, puzzles, brain twisters, etc.), search elements, prizes, etc. all should be taken into account when making final calculation;

7. Tips are an integral part of the quest excursion, it is an opportunity to get help in solving and completing tasks, in the course of passing the route of the quest excursion. Tips can be needed due to the characteristics of the group, the complexity of tasks, etc., when it is necessary to get back the tourists to the route, direct or help them. It is important to discuss these points in advance, for example, in what situations the tips can be given, their number, the impact of tips on the final result (increase in time, additional tasks, etc.) in this column we include fines for violation of the rules and using a way around the quest route. All these points should be reflected in a special document Safety Provisions and Rules of the Quest Excursion;

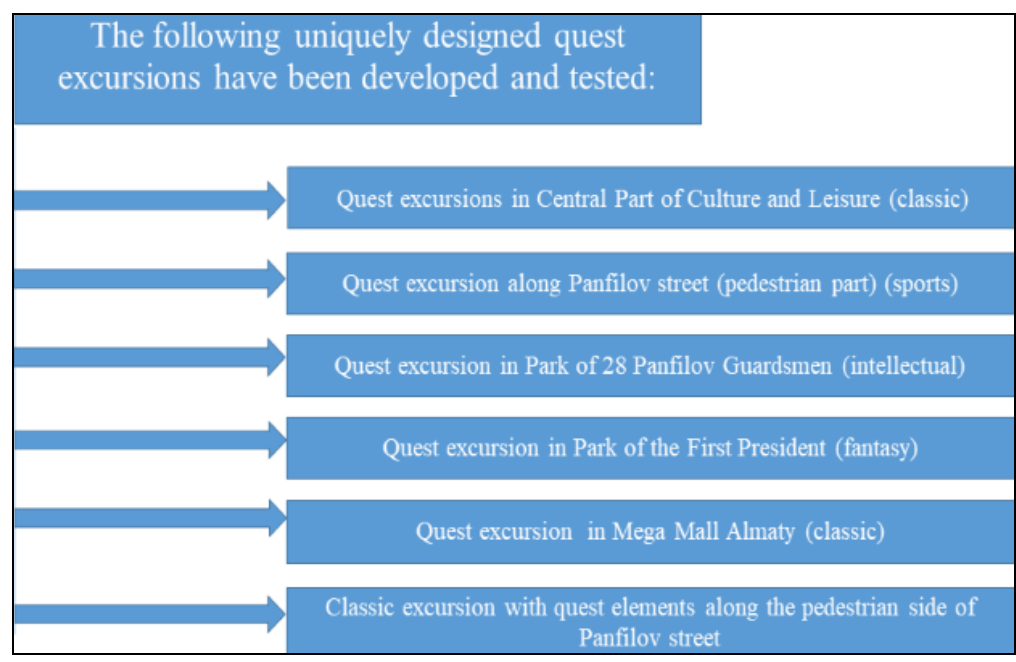

Figure 6. Quest excursions of different focuses (compiled by the author)

8. The process and results of the quest excursion should be analyzed, recorded and taken into account for further use in such work. In the course of the research, we implemented all the above-mentioned principles and created uniquely designed quest excursions, presented in Figure 6, which fully reflect the specifics of this direction. So, the following quest excursions around the city of Almaty were developed:

1) Quest excursion in Central Park of Culture and Leisure, a search quest that combines educational and sports elements;

2) Quest excursion along the pedestrian part of Panfilov street, the main focus is sport with a combination of history, local history, urban planning, as this route is full of attractions not only of the city, but also of the national level;

3) Quest excursion in Park of 28 Panfilov Guardsmen, intellectual focus, fully revealing all the local history features of objects located in this area;

4) Quest excursion in Park of the First President, fantasy focus, i.e. a large area of the location was "transferred" to an alternate reality, when the scenario was created, supplemented with artifacts and treasure; 
5) Indoor quest excursion with a classic focus in Mega Mall Almaty with features for safety and internal documents, in this case, there are the principles of active learning, sports activities, history and local history, as the objects involved in the route are specific and information rich;

6) A classic excursion with elements of a quest along the pedestrian part of Panfilov Street with concentration of objects of excursion interest and information saturation of not only the Main, but also the Accompanying objects of the route.

Thus, the developed quest excursions are uniquely designed by the authors, correspond to the developed methodology and contribute to the creation of a high-quality excursion and tourist product necessary for the development of domestic and inbound tourism.

Thus, the development of quest excursions contributes to the high-quality provision of excursion services, which combines information and interactive components, which is undoubtedly interesting for the modern tourist market.

- Classic excursion with quest elements along the pedestrian part of Panfilov Street (Figure 7) consists of two parts:

1) The classic part of the excursion along the route: Panfilov Street.

2) Interactive part of the excursion, task: "Prove or disprove 6 task options for 5 questions that require not just finding the answer, but also proving it." This form allows tourists not just to listen to the information during the excursion, but to hear and see everything that the guide considers necessary, to be an active participant.

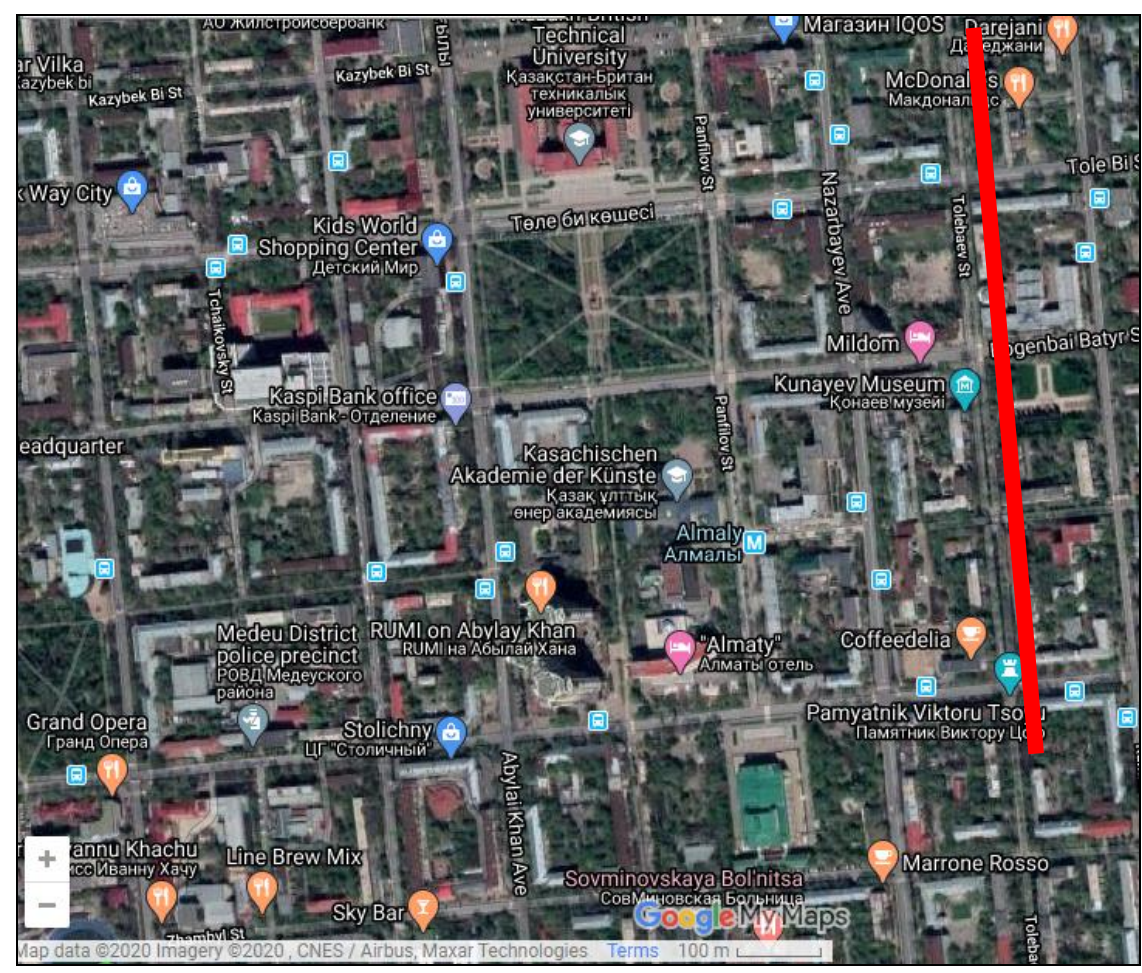

Figure 7. The route of the quest excursion along

the pedestrian part of Panfilov Street [https://www.google.com/maps]

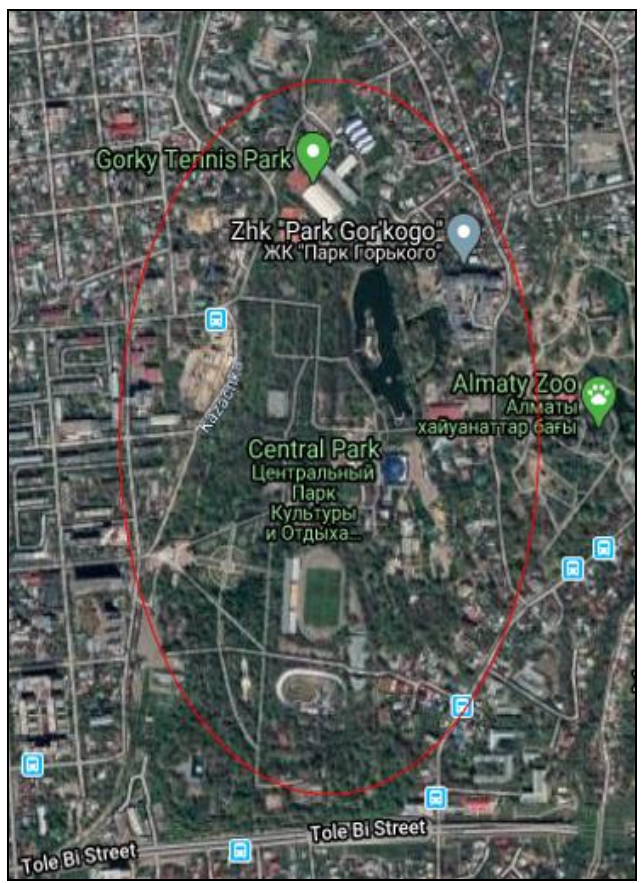

Figure 8. Map of Central Park of Culture and Leisure (Almaty) [https://www.google.com/maps]

Examples of the interactive part of the excursion:

A) Prove or disprove:

1. The building of the Abay Opera House was built in 1934.

2. The number of benches on the right side of a pedestrian street is equal to the number of young trees on the left side (along the route from the South to the North).

3. The first fountain in the city now has no water and it does not work

4. The number of arches in the Nedelka fountain is equal to the number of days of the week.

5. Monument to A. Moldagulova and M. Mametova faces the old square, currently Astana square.

B) Make a series of photos "The most..."

a. The funniest.

b. The most original.

c. The brightest.

d. The most crowded (group photo, the more people and the closer they stand, the better).

e. The most cozy (everyone interprets the word "cozy" in their own way).

C) Hunting for birds photo (take a photo with this bird and answer questions).

a. Find an exotic bird that indicates the direction of the cardinal directions. What bird is it? Where does it live? (Toucan, lives in forests from southern Mexico to Northern Argentina, location of the bird is Irish Pub, on the left wall from the main entrance).

b. Find a bird that is a symbol of love and tell an interesting fact about it (swan, which cannot survive without its mate, location is Fountain of Lovers).

c. Find a bird that is a symbol of peace and tell an interesting historical fact about it (which was a postal bird, the location is victory monument in the square in front of KBTU) (you can take a photo with a live pigeon).

Summing up the results of the program. Tourists get not only the opportunity to walk along the route on their own, but also, after completing the task, make good photos.

- Organization of the quest excursion in Central Park of Culture and Leisure. The quest is designed for 3 teams. Each team has its own route through the park and has its own special tasks. The minimum possible time for each route is 45 minutes, and the best time shown during the quest is 1 hour and 45 minutes. The main idea of the quest is to get ahead of the rival teams in finding the treasure that is hidden at the last point of the route. The location map is shown in Figure 8. 
Each route from the start point to the finish point, together with the time for tasks, is at least 45 minutes, the real time is 1 hour 45 minutes. The passage time from point to point is 5-10 minutes, and the time for doing the tasks at each point is 5-10 minutes. At each point, teams should send photos from the place to get further tasks (and this will also help the organizers track the places and time of the quest). The start and finish points are the same for all teams.

The start is at the main gate, in front of the park map. Each team draws lots, thereby choosing a route. The first puzzles are given to find the next point. The finish is at the fountain with Argali, near the willow, photos from the route testing are shown in Figure 9.
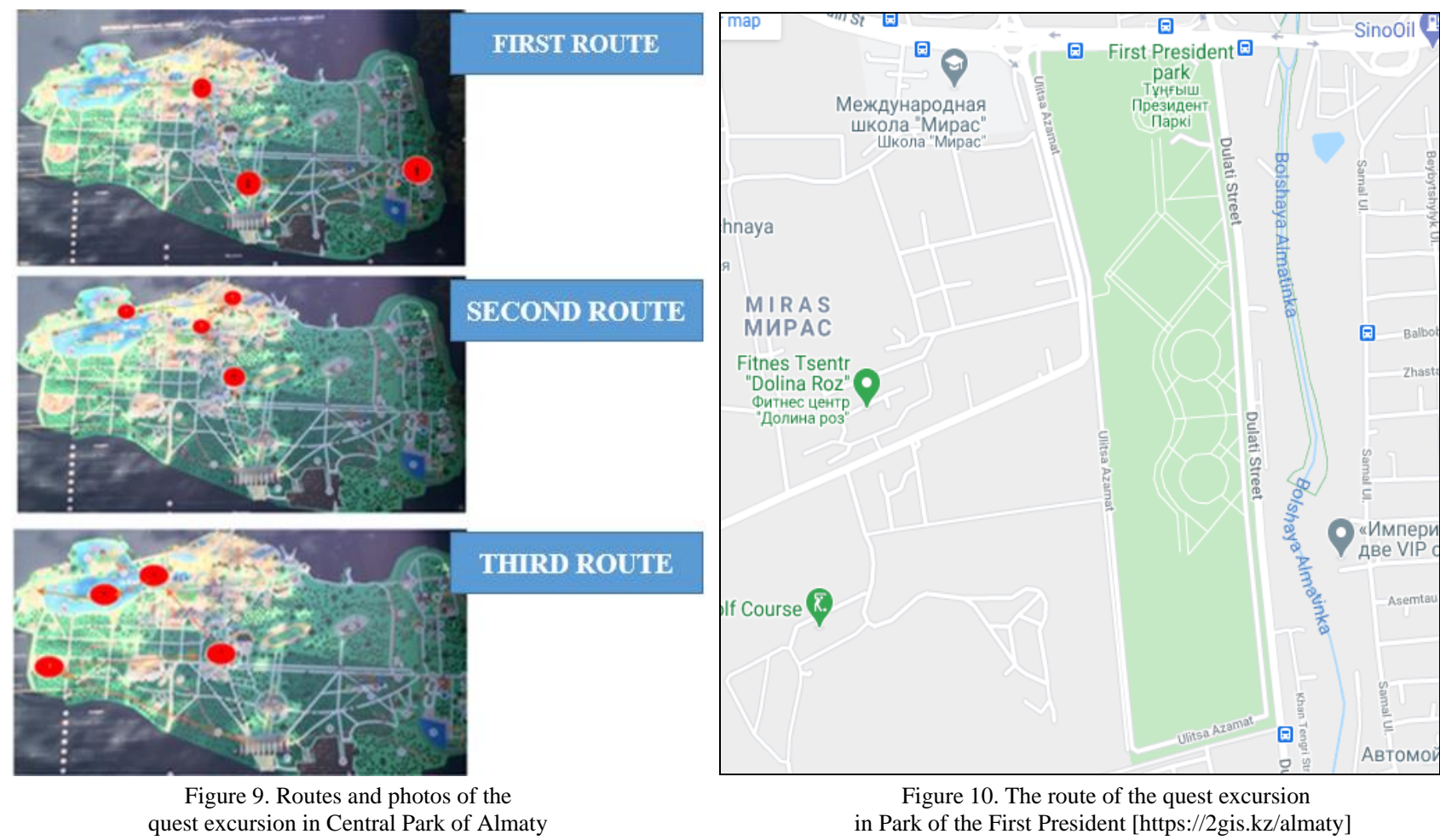

Figure 10. The route of the quest excursion quest excursion in Central Park of Almaty in Park of the First President [https://2gis.kz/almaty]

- Quest excursion in Park of the First President. Fantasy - the presence of a different storyline (Figure 10):

1) Invented story that precedes the quest.

2) Developed single route with tips. A distinctive feature, different place of "entry" in the quest, participation from 1 to 5 teams.

- Quest excursion in Park of 28 Panfilov Guardsmen (intellectual). The quest is designed with maximum emphasis on exploring the attractions of the park. The single route is shown in Figure 11, the presence of organizers at certain points that not only coordinate the process, but also give tour information about the objects.
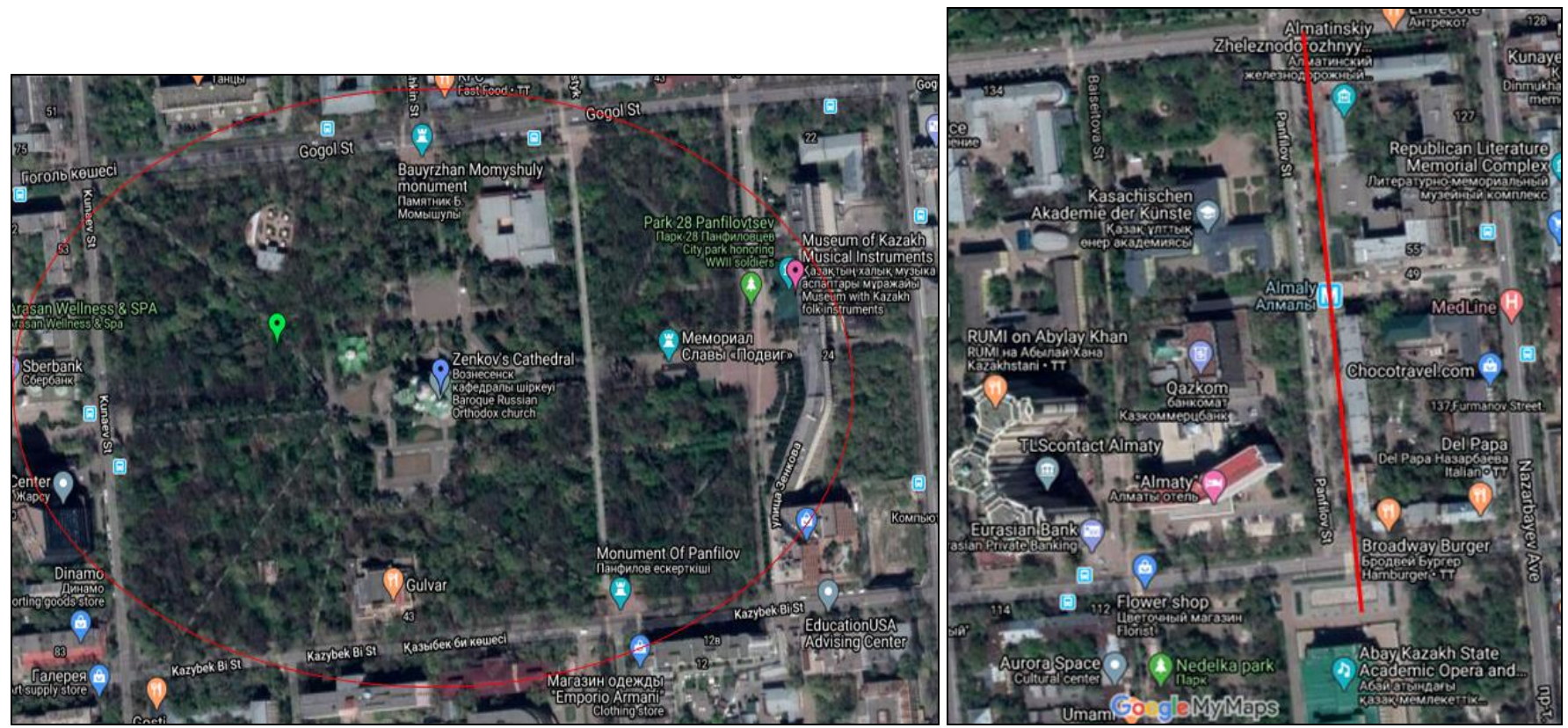

Figure 11. Route of the quest excursion in Park of 28 Panfilov Guardsmen [https://www.google.com/maps]

Figure 12. Route of the quest excursion along Panfilov Street (pedestrian part) [https://www.google.com/maps]

- Quest excursion along Panfilov Street (pedestrian part (sports). This quest excursion combines intellectual and creative tasks of a sports focus, but taking into account the possibility of passing the route by different categories of tourists (Figure 12). The minimum route time 
is 45 minutes, and the optimal time is 1 hour and 30 minutes (excluding organizational time). One route with tasks. At the finish line, a sheet of questions is issued, after answering which, the fastest and correctly answered team receives a code from the lock that contains the prize.

Thus, the developed and tested quest excursions contribute to:

- Improving the quality of training of tourist personnel, which is a priority for the development of domestic and inbound touri sm. Special attention is paid not only to the study of developed quest excursions, but also to the method of creating these directions in tourism. Thus, the method developed by the authors allows us to effectively form stable competencies in the field of creating, implementing and promoting quest excursions.

- Creation of a new tourist product in Almaty, necessary for the development of domestic and inbound tourism of the Republic of Kazakhstan. The innovative product will expand the base of services provided to tourists, and qualitatively affect the variety of leisure facilities.

- Extending knowledge about Almaty, its history, culture, modern development, etc., which is necessary to create a favorable image of the country, its development and promotion in the world tourism arena.

- A variety of leisure activities for tourists in Almaty, providing innovative forms of organizing sightseeing services, as well as creating animated events aimed at attracting tourist flows.

- Expansion of the tourist potential of the city, its development and popularization among residents and visitors of the city, domestic and international tourist flows.

\section{CONCLUSIONS}

1. In the article, the authors proposed clarification of the term "quest excursion", which fully reflects the specifics of this form of excursion service.

2. The authors of the article have developed a unique method of creating quest excursions as a special form of organizing excursion services, combining elements of information and interactivity, while special attention is paid to the stages of the process and argumentation of each element of the method, which can qualitatively affect the level of organization of excursion services.

3. This article presents the results of the implementation of the uniquely designed methodology for creating quest excursions, namely, the development of 6 full-fledged quest excursions on the territory of Almaty, tested and implemented in practice.

4. The methodology developed by the authors of the article will allow to influence the development of domestic and inbound tourism, as well as to become a guide for creating quest excursions at the regional and international level.

\section{Acknowledgments}

The results of the research presented in this article will make it possible to develop effectively quests excursions according to the methodology proposed by the authors, and will also become educational and methodological material for the training of specialists in the tourism industry. The data presented in the article are practical and innovative in the excursion service in the Republic of Kazakhstan. Quest excursions expand the offer on the domestic and inbound tourism market of Kazakhstan.

\section{REFERENCES}

Akbar, I., Yang, Z., Mazbayev, O., Seken, A., \& Udahogora, M. (2020). Local residents' participation in tourism at a world heritage site and limitations: aksujabagly state nature reserve, western Tian-Shan, Kazakhstan. GeoJournal of Tourism and Geosites, 28(1), 35. https://doi.org 10.30892/gtg.28103-450

Alekseyeva, N.D. (2015). Quest tour as an innovative form of excursion activity. N.D. Alekseeva, E.V. Ryabova, Vector of science of the Togliatti state unthat, Ser. Pedagogy, Psychology, 1, 14-18 (in Russian).

Alexandrova, A.Yu. (2015). Geography of tourism: textbook. MKnoRus, ed., pp. 592 (in Russian).

Bulygina, I.I. (2016). Patriotic tourism as an effective means of education. I.I. Bulygina, Professional education in Russia and abroad: materials of Interregion Youth Scientific Image. Forum Patriotism, Education, Students, Kemerovo, Kemerovo, Kuzbass reg. in-t development of prof. education, 4 (24), 22-25 (in Russian).

Burke, J.R., \& Onwuegbuzie, A.J. (2004). Mixed methods research: A research paradigm whose time has come. Educational Researcher, United States, Washington, DC, SAGE Publications Inc, 33(7), 14-26.

Imangulova, T.V., Gubarenko, A.V., \& Evstifeeva, T.V. (2019). Tourist-toponymic dictionary of Almaty region: Textbook. Almaty, Kazastan, pp.167.

Imangulova, T.V., Gubarenko, A.V., \& Luterovich, O.G. (2019). Development of the official audio guide of the city of Almaty as an innovative form of excursion service. Questions of geography and Geoecology, KKSON RK, 4, 19-23 (in Russian).

Karatabanov, R.A., Janaleyeva, K.M., \& Pashkov, S.V. (2020). Kazakhstan's multiethnicity: factor of inter-ethnic tension and development of cross-border tourism. GeoJournal of Tourism and Geosites, 29(2), 732-745. https://doi.org/10.30892/gtg.29227-502

Kedrova, I.V. (2017). Improvement of the theoretical foundations of excursione: classification of the city. Network scientific and practical journal, Scientific Result, Series Technologies of business and service, 1, 3-10 (in Russian).

Kuteeva, E.R., \& Pospelov, S.V. (2015). Quest-excursion as a form of modern excursion activities. Management of the XXI century: crisis strategy and risk management/collection of scientific articles on materials of XV International scientific-practical conference. Russian state pedagogical University. A. I. Herzen, Institute of Economics and management, (in Russian), SPb. 214-216.

Luterovich, O.G., \& Yagofarov, G.F. (2016). Ekskursionnaya deyatelnost v Respublike Kazakhstan [Excursion Activities in the Republic of Kazakhstan]. Almaty, Service Press publishing house, pp.301.

Morgan, D. (2013). Integrating qualitative and quantitative methods: A Pragmatic approach. - Thousand Oaks, CA, Sage Publications, pp. 288.

Nekhayeva, N., \& Morozkina, K. (2017). Quest tourism as an innovative form of tour. Journal Innovations in Science, 7 (68), 1 (in Russian).

Pospelova, S.V. (2017). Interactive excursion activities. Scientific result. Business and service technologies. T.3, 2.

Raikov, B.Ye. (1922). Metodika i tekhnika vedeniya ekskursiy [Methodology and technique of conducting excursions]. St. Petersburgb, pp. 116.

Tătar, C.F., Herman, G.V., \& Gozner, M. (2018). Tourist guides' contribution to sustainability in Romania. GeoJournal of Tourism and Geosites, 21(1), 282287. https://doi.org/10.30892/gtg.21122-287

Yemelyanov, B.V., \& Ekskursovedeniye, M. (2001). Tourist Guidance. Soviet Sport, pp.214.

Zakiryanov, B.K., Luterovich, O.G., Orazymbetova, B.K., Arstanov, B.A., Gubarenko, A.V., \& Semibratova, P.A. (2018). 200 sightseeing objects of Almaty. Textbook-Almaty: Servis Press, pp.507.

Zhuravlev, V.I., Kraevsky, V.V., \& Krupina, V.I. (1998). Pedagogy. Pedagogical society of Russia, pp. 640.

*** Law of the Republic of Kazakhstan dated June 13, 2001 No. 211-II, On tourist activities in the Republic of Kazakhstan, with amendments and additions as of 01.07.2019. https://online.zakon.kz/ 